\title{
Erratum to: Landing point location algorithm based on asynchronous time difference of arrival (ATDOA) method
}

\author{
Pengyu $\mathrm{Li}^{1,2} \cdot$ Lufeng Che $^{1}$
}

Published online: 11 January 2017

C) Springer-Verlag Berlin Heidelberg 2016

\section{Erratum to: Microsyst Technol \\ DOI 10.1007/s00542-016-3162-2}

Unfortunately, the first affiliation in the article has been published with incorrect laboratory details.

The correct details are given below:

Science and Technology on Microsystem Laboratory, Shanghai Institute of Microsystem and Information Technology, Chinese Academy of Sciences, Shanghai 200050, China

The online version of the original article can be found under doi:10.1007/s00542-016-3162-2.

\section{Pengyu Li}

4010087@qq.com

1 Science and Technology on Microsystem Laboratory,

Shanghai Institute of Microsystem and Information

Technology, Chinese Academy of Sciences,

Shanghai 200050, China

2 University of Chinese Academy of Sciences, Beijing 100039, China 